\title{
CONSIDERAÇÕES SOBRE PROASPHONDYLIA FELT (DIPTERA, CECIDOMYIIDAE) COM DESCRIÇÕES DE DUAS ESPÉCIES NOVAS ASSOCIADAS COM GUAPIRA OPPOSITA (VELLOSO) REITZ (NYCTAGINACEAE)
}

\author{
Valéria Cid Maia ${ }^{1}$
}

\begin{abstract}
CONSIDERATIONS ABOUT PROASPHONDYLIA FELT (DIPTERA, CECIDOMYIIDAE) WITH DESCRIPTION OF TWO NEW SPECIES ASSOCIATED WITH GUAPIRA OPPOSITA (VELLOSO) REITZ (NYCTAGINACEAE). Proasphondylia formosa, sp.n. and Proasphondylia guapirae, are described. A brief diagnosis of the genus and and a key to segregate males of the known species are also provided.

KEY WORDS. Diptera, Cecidomyiidae, new species, Brazil
\end{abstract}

O gênero Proasphondylia foi registrado, até o momento, apenas no Brasil. FELT (1915) descreveu o gênero e a espécie-tipo - P. brasiliensis (macho, fêmea e pupa), com material proveniente de Pernambuco.

MÖHN (1962) redescreveu, com ilustrações, o macho e a fêmea desta espécie, utilizando o material tipo.

Aqui são apresentadas as descrições de $P$. formosa, sp.n. e de $P$. guapirae, sp.n. com suas respectivas galhas, da planta hospedeira. Uma breve diagnose do gênero e uma chave para segregação dos machos das espécies conhecidas são fornecidas.

\section{Proasphondylia Felt, 1915}

Diagnose. Palpo com três artículos; garras delicadas e pulvilo rudimentar; ovipositor protátil não atingindo a metade do comprimento do abdômen, com porção basal larga e macia, e porção distal subaciculada. Gonóstilo do macho subapical, curto, largo e pectinado apicalmente.

Considerações. Gênero neotropical com apenas três espécies conhecidas, incluindo a descrita neste trabalho, todas com ocorrência assinalada no Brasil. Até o momento, os tipos de galhas induzidas por elas e a planta hospedeira eram desconhecidos na literatura.

1) Museu Nacional, Quinta da Boa Vista, São Cristóvão, 20940-040, Rio de Janeiro, Rio de Janeiro, Brasil. Bolsista da CAPES. 
Chave para segregação dos machos das espécies de Proasphondylia

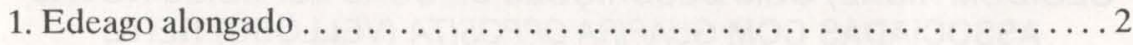

- Edeago glossiforme; hipoprocto bilobado, mais estreito que a base do edeago formosa

2. Edeago com uma pequena reentrância apical; hipoprocto bilobado, mais estreito que a base do edeago (Fig. 72b de MÖHN, 1962) ..... brasiliensis

- Edeago sem reentrância apical; hipoprocto bilobado, mais largo que a base do edeago .................................... guapirae

\section{Proasphondylia guapirae, sp.n. \\ Figs 1-6}

Diagnose. Pupa: antenas desprovidas de chifres; face: um par superior de espinhos cefálicos triangulares, serreados na margem suprior; dois pares de papilas inferiores (um par setoso e um par sem cerda) e três pares de papilas laterais (dois pares sem cerda e um par com cerda). Espiráculo protorácico como uma mancha mais escura.

Macho. Com gonóstilo retangular; edeago alongado, sem reentrância apical; hipoprocto bilobado e piloso, mais largo que a base do edeago; cerco formado por dois lobos elipsoidais e pilosos.

Pupa. Coloração: castanho-clara. Comprimento 3,5mm; cabeça (Fig. 1): antenas desprovidas de chifre; um par de cerdas apicais dorsais com 0,06mm; face com um par superior de espinhos cefálicos triangulares, serreados na margem superior; dois pares de papilas inferiores (um par setoso e um par sem cerda) e três pares de papilas laterais (dois pares sem cerda e um par com cerda). Tórax: espiráculo como uma mancha mais escura. Abdômen: segmentos II-VIII completamente cobertos pos espinhos diminutos, com uma fileira irregular de espinhos dorsais bem desenvolvidos e outra de espinhos dorsais menores. Face ventral com envoltório da asa atingindo a metade do segmento III e envoltório dos $1^{\circ}, 2^{\circ}$ e $3^{\circ}$ pares de pernas atingindo, respectivamente, o limite das metades basal e distal, a metade do terço médio e o limite dos terços médio e distal do segmento VI.

Macho. Comprimento: corpo 3,4-3,8mm; asa 3,14mm $(n=5)$. Cabeça: olhos com facetas hexagonais, intimamente aproximadas. Labelo com cerdas medianas e laterais, hipofaringe setuloso apicalmente, face com cerdas, flagelômeros cilíndricos, ornados como na figura 2. Tórax: asa como na figura 3. Pernas: com garras simples, empódio rudimentar e pulvilos ausentes. Genitália (Fig. 4): gnóstilo retangular; edeago alongado, sem reentrância apical, hipoprocto bilobado e piloso, mais largo que a base do edeago; cerco com dois lobos elipsoidais, pilosos, completamente separados um do outro.

Fêmea. Semelhante ao macho, diferindo no que segue. Comprimento: corpo $3,4-3,6 \mathrm{~mm}$; asa $3,2 \mathrm{~mm}(\mathrm{n}=6)$. Cabeça: flagelômeros ornados como na 


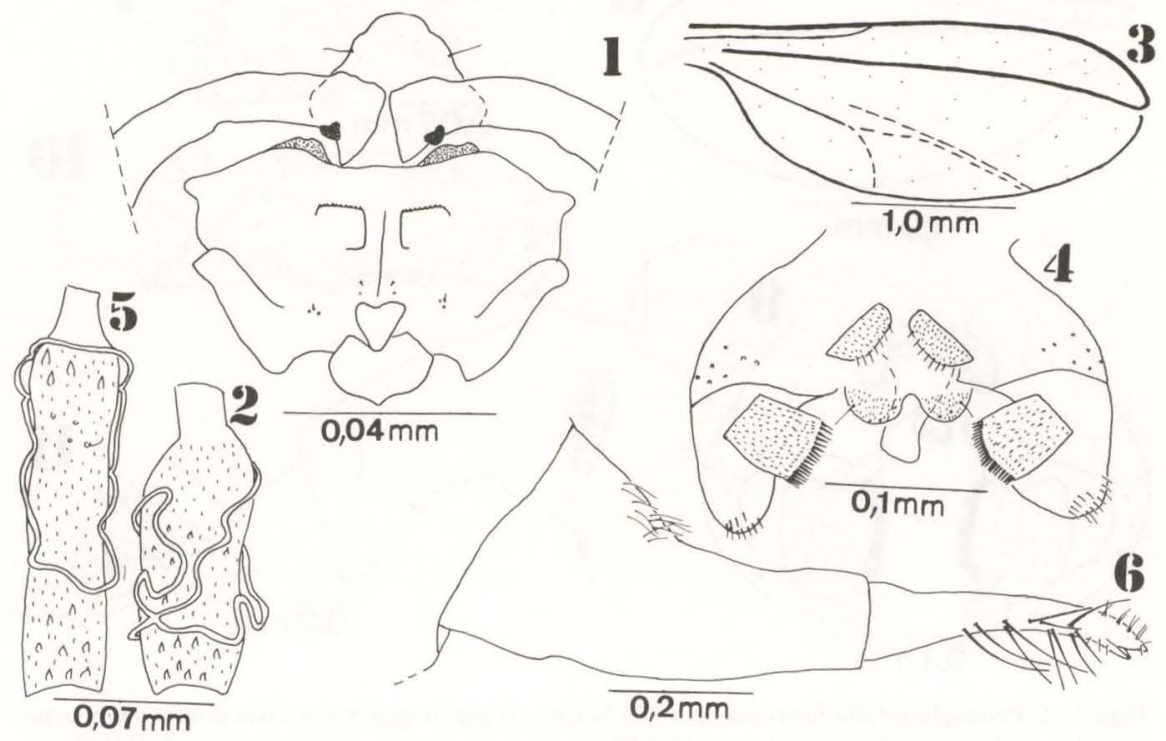

Figs 1-6. Proasphondylia guapirae, sp.n. (1) Pupa, região cefálica, vista ventral; (2) macho, quinto flagelômero, vista dorsal; (3) macho asa; (4) macho, genitália, vista dorsal; (5) fêmea, quinto flagelômero, vista dorsal; (6) fêmea, ovipositor, vista dorso-lateral.

figura 5. Ovipositor: como na figura 6.

Holótipo macho. BRASIL: Rio de Janeiro, Arraial do Cabo, 21-IX-1987, Valeria Cid Maia col.; obtido de galhas caulinares em Guapira opposita (Nyctaginaceae) (MNRJ). Parátipos. Mesma procedência e coletor do holótipo: uma fêmea, 11-VIII-1987; um macho e 13 fêmeas, 21-IX-1987; duas pupas, 21-IX-1987 (MNRJ).

Galha. Formada por uma modificação da epiderme do caule, de coloração marrom, plurilocular, com uma única larva em cada câmara interna. A larva empupa no interior da galha.

\section{Proasphondylia formosa, sp.n.}

Figs 7-11

Diagnose. Macho com gonóstilo retangular; edeago glossiforme; hipoprocto mais estreito que a base do edeago; cerco com dois lobos reniformes.

Macho. Comprimento: corpo 3,6mm; asa: 2,30mm. Cabeça: olhos com facetas circulares intimamente aproximadas. Labelo com cerdas em toda a superfície dorsal, hipofaringe setuloso no ápice e face com cerdas desenvolvidas; flagelômeros cilíndricos ornados como na figura 7. Tórax: asa como na figura 8. Pernas com garras simples, empódio rudimentar e pulvilos ausentes. Genitália: gonóstilo retangular, edeago glossiforme, hipoprocto bilobado e piloso, mais estreito que a base do edeago, cerco com dois lobos reniformes 


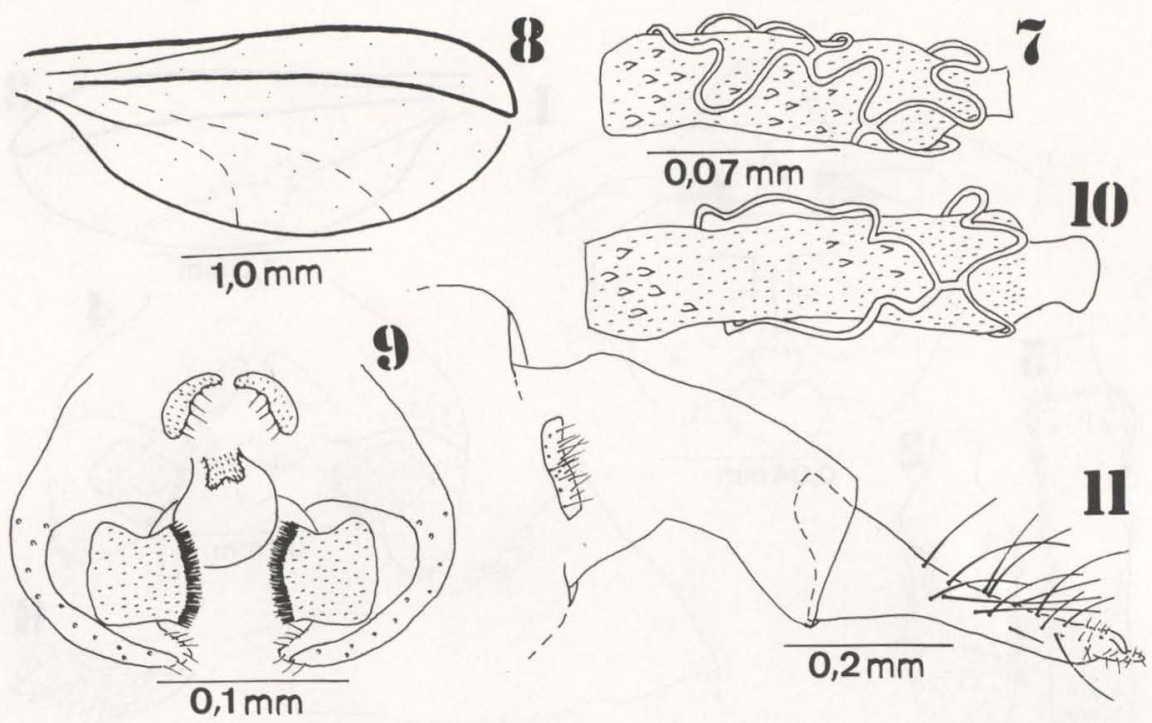

Figs 7-11. Proasphondylia formosa, sp.n. (7) Macho, quinto flagelômero, vista dorsal; (8) macho, asa; (9) macho, genitália, vista dorsal; (10) Fêmea, terceiro flagelômero, vista dorsal; (11) fêmea, ovipositor, vista dorsal.

pilosos, completamente separados um do outro (Fig. 9).

Fêmea. Semelhante ao macho, diferindo no que segue. Comprimento: corpo 3,5mm; asa 2,9mm. Cabeça: hipofaringe setuloso no ápice, pré-ápice com setula lateral; flagelômeros ornados como na figura 10. Ovipositor: como na figura 11.

Holótipo Macho. BRASIL: Rio de Janeiro, Restinga de Barra de Maricá, 09-IX-1987, Valéria Cid Maia col.; obtido de galhas de ramos em Guapira opposita (Nyctaginaceae) (MNRJ). Parátipos. Mesma procedência e coletor do holótipo, um macho, 09-IX-1987 e uma fêmea, 09-IX-1987 (MNRJ). Obtidos da mesmea forma.

Galha. Esférica, de coloração avermelhada, número de câmaras internas variado (1-6), presente em ramos e com opérculo circular quando madura.

AGRADECIMENTOS. Ao Dr. Raymond J. Gagné, (Systematic Entomology Laboratory, USDA), pelo auxílio na identificação do material.

\section{REFERÊNCIAS BIBLIOGRÁFICAS}

FELT, E.P. 1915. New genera and species of gall midges. Proc. U.S. National Mus. 48 (2072): 195-211.

MÖHN, E. 1962. Studien über neotropische gallmücken (Diptera, Itonididae).

Brotéria, Ciências Naturais, 31: 211-239. 